\title{
Abdominal Radical Trachelectomy
}

Takuma Fujii, MD, PhD ${ }^{1}$

${ }^{1}$ Department of Obstetrics and Gynecology, Fujita Health University, Aichi, Japan

Surg J 2021;7(suppl S2):S97-S102.
Address for correspondence Takuma Fujii, MD, PhD, Department of Obstetrics and Gynecology, Fujita Health University, 1-98, Dengakugakubo, Kutsukakecho, Toyoake, Aichi 470-1192, Japan (e-mail: fujiit44@fujita-hu.ac.jp).

\section{Introduction}

The number of patients diagnosed with early stage cervical cancer during their childbearing years has been increasing. It is estimated that $43 \%$ of all women with cervical cancer in the United States are diagnosed when they are younger than 45 years of age. ${ }^{1}$ Because of this tendency, there has been an increased emphasis on fertility-sparing surgery for early invasive cervical cancer. Radical trachelectomy is a procedure that expands the options for fertility-preserving surgery. The original procedure reported by Dargent et al consisted of radical vaginal trachelectomy by laparoscopy. ${ }^{2}$ Abdominal radical trachelectomy, which involves celiotomy instead of laparoscopy, was first reported by Smith et al in $1997 .{ }^{3}$ When we decided to perform radical trachelectomy at our institution, we selected open surgery due to its convenience when conversion to the standard procedure is necessary. When performing this operation, we routinely resect the cardinal ligament (to the same extent as during standard radical hysterectomy), preserve the uterine artery, and decide on the appropriate extent of cervical resection in each patient. ${ }^{4}$

\section{Surgical Steps}

1. Opening of the abdominal wall and exploration. $\downarrow$

2. Pelvic lymphadenectomy.

published online October 22, 2021
DOI https://doi.org/ $10.1055 / \mathrm{s}-0041-1728750$. ISSN 2378-5128. $\downarrow$

3. Resection of the paracervical/parametrial tissues. $\downarrow$

4. Opening of the vagina and preparation of the vaginal wall.

$\downarrow$

5. Partial resection of the cervix. $\downarrow$

6. Neocervix plasty. $\downarrow$

7. Closure of the retroperitoneal space. $\downarrow$

8. Closure of the abdomen.

\section{Indications for Abdominal Radical Trachelectomy}

- Desire for fertility-sparing procedure and age younger than 45 years.

- Fully accepted informed consent about the option of choosing either abdominal radical hysterectomy or abdominal radical trachelectomy.

- Fédération Internationale de Gynécologie et d'Obstétrique (FIGO) stage 1A1 cervical cancer with lymphovascular space involvement.

(c) 2021. The Author(s).

This is an open access article published by Thieme under the terms of the Creative Commons Attribution-NonDerivative-NonCommercial-License, permitting copying and reproduction so long as the original work is given appropriate credit. Contents may not be used for commercial purposes, or adapted, remixed, transformed or built upon. (https://creativecommons.org/ licenses/by-nc-nd/4.0/)

Thieme Medical Publishers, Inc., 333 Seventh Avenue, 18th Floor, New York, NY 10001, USA 


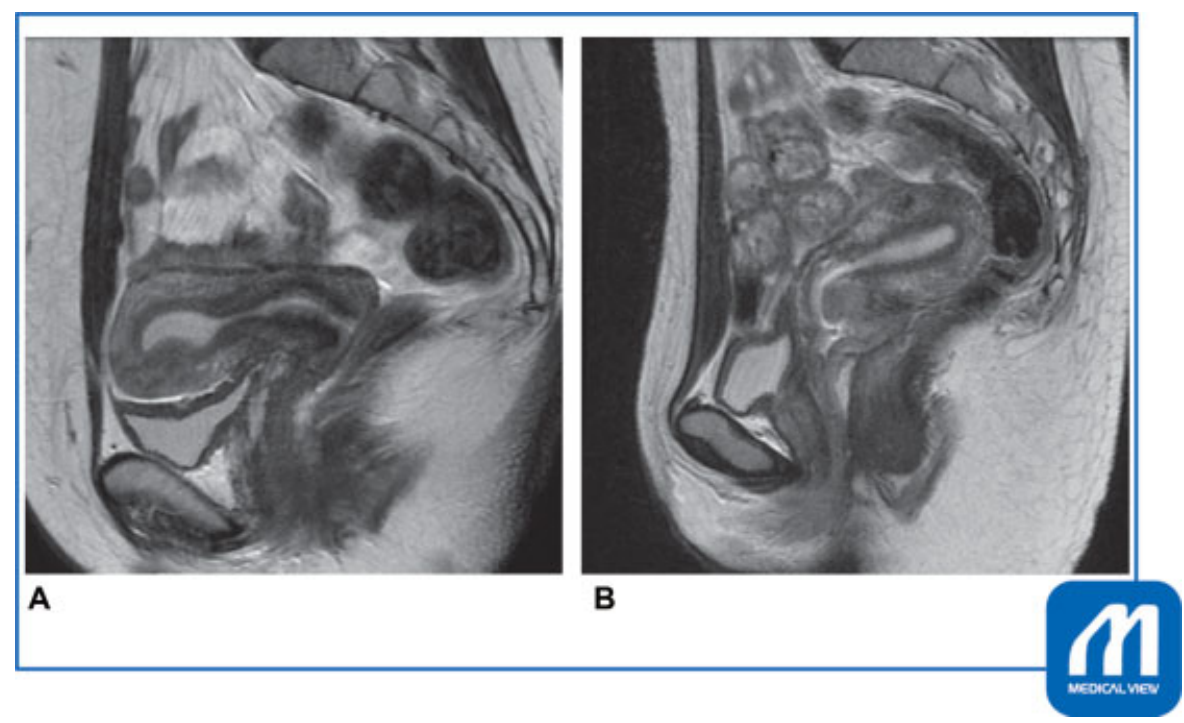

Fig. 1 Application of the trachelectomy determined by magnetic resonance imaging (MRI).(A) Applicable. Tumor was located in the anterior lips of the portio with shallow invasion and $18 \mathrm{~mm}$ in width. The remnant neocervix could be secured for more than $10 \mathrm{~mm}$ in length. (B) Not applicable. Tumor was located inside the posterior lips of the portio with deep invasion and $20 \mathrm{~mm}$ in diameter. The remnant neocervix could not be secured for more than $5 \mathrm{~mm}$ in length for maintenance of a future baby in utero. (Reproduced with permission from Fujii T, Aoki D. In: Konishi I, Hiramatsu Y, Sakuragi N, Takeda S, eds. OGS NOW, No.5. (Japanese). Tokyo: Medical View; 2011:86-93. Copyright @ Medical View.)

- FIGO stage IA2 or stage IB1 cervical cancer, not exceeding $3 \mathrm{~cm}$ in tumor size; best indication is tumor size $\leq 2 \mathrm{~cm}$.

- No involvement of the upper endocervical canal (-Fig. 1) and no evidence of lymph node metastasis as determined by magnetic resonance imaging (MRI)/computed tomography (CT).

- No additional abnormal lesions (including in the vagina) by colposcopy.

- Securement of the distal margin of the neocervix at least $5 \mathrm{~mm}$ removed from the margin of the tumor by MRI.

- Plasty of the neocervix with $5-\mathrm{mm}$ length $(10 \mathrm{~mm}$ if possible).

- Squamous cell carcinoma or well-differentiated adenocarcinoma.

\section{Contraindications for Abdominal Radical Trachelectomy}

- Prior pelvic radiation therapy.

- Poorly differentiated adenocarcinoma or small cell carcinoma.

\section{Preoperative and Perioperative Preparation}

Preoperative preparation is the same as that for abdominal radical hysterectomy. It is good practice to place a ureteral catheter in advance to prevent ureteral injury in patients with certain conditions such as obesity. (The rate of ureter injury is reported to be less than $1 \%$ in abdominal radical hysterectomy as well as in trachelectomy. If a ureteral fistula is present, it can be problematic to proceed with assisted reproductive technology after surgery.)

The vaginal microbiome, including anaerobes, often causes pelvic inflammatory disease such as lymphocyst infection in the perioperative period. Vaginal disinfection before and during surgery with povidone-iodine is useful to minimize the risk of infection.

\section{Surgical Technique}

1. Opening of the abdominal wall and exploration: the vertical incision is made from over the navel to the pubic symphysis. The surgeon should be careful to not injure the infundibulopelvic ligaments.

2. Pelvic lymphadenectomy: the retroperitoneal space is open between the round ligament and the infundibulopelvic ligaments. The paravesical and pararectal spaces are checked for cancer spread. Bilateral pelvic lymph node dissection is performed up to the level of the bifurcation of the common iliac artery. The extent of the pelvic lymphadenectomy is identical to that in a standard radical hysterectomy and includes the common iliac, presacral, internal/external iliac, cardinal, obturator, and inguinal nodes. Frozen sections of any enlarged lymph nodes are taken for histopathological examination. If cancer cells are detected in the lymph nodes, the planned procedure is abandoned and the operation is converted to a conventional radical hysterectomy.

3. Dissection of the vesicouterine ligament (anterior/posterior leaves), cardinal ligaments, sacrouterine ligaments, and paracolpium: the ureter is mobilized from the medial sheath of the broad ligament up to the level of the cardinal ligament. The uterine artery is identified at its origin from the internal iliac artery and gently preserved (-Figs. 2 and $\mathbf{3}$ ). The anterior leaf of the vesicouterine ligament is cut and divided. The deep uterine vein is cut and divided. The stump of the deep uterine vein is separated from the hypogastric nerves for nerve-sparing surgery. The vagina 


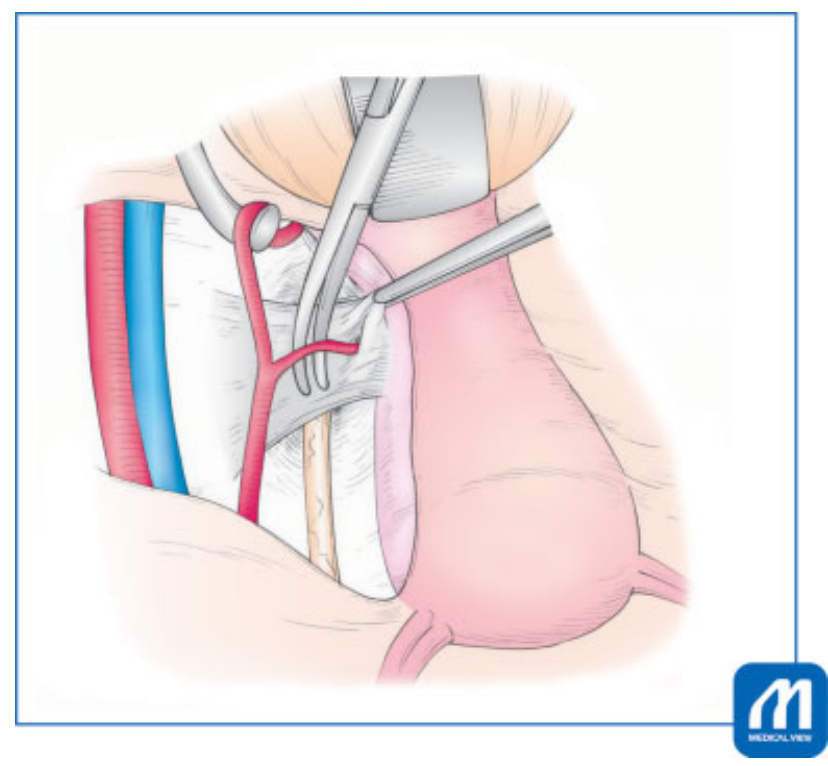

Fig. 2 Preservation of the uterine artery. The uterine artery over the ureter is isolated and preserved. (Reproduced with permission from Fujii T, Aoki D. In: Konishi I, Hiramatsu Y, Sakuragi N, Takeda S, eds. OGS NOW, No.5. (Japanese). Tokyo: Medical View; 2011:86-93. Copyright $\odot$ Medical View.)

and rectum are separated to cut the sacrouterine and rectouterine ligaments. The posterior leaf of the vesicouterine ligament is cut and divided. The paracolpium is cut and divided (-Fig. 4).

4. Opening of the vagina and preparation of the vaginal wall: the upper level of the vaginal wall, approximately $2 \mathrm{~cm}$ in length, is clamped by Wertheim forceps to prevent spillage

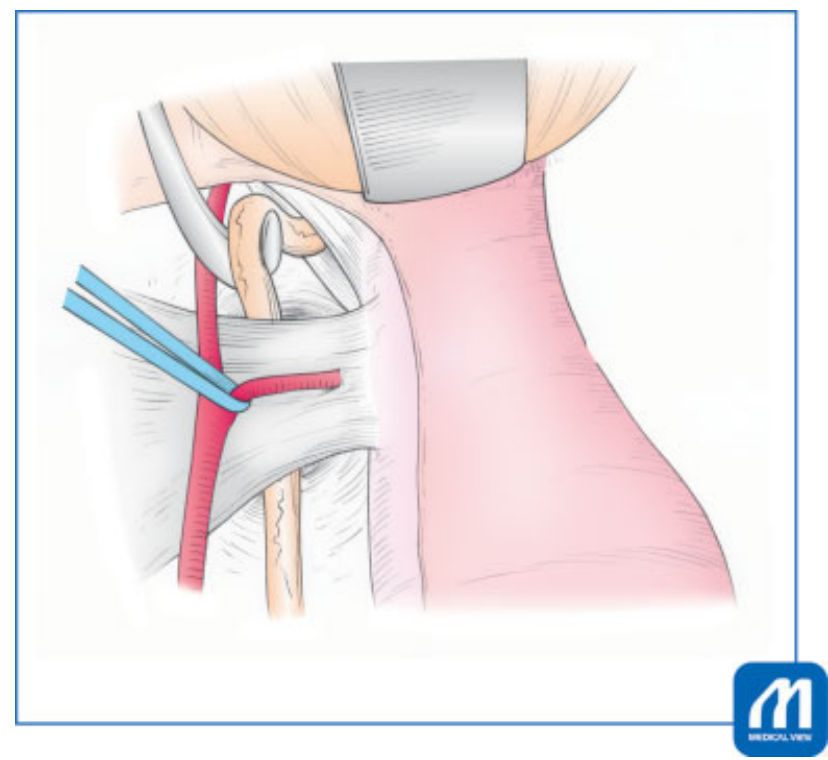

Fig. 3 Holding the ureter between the uterine artery and leaves of the vesicouterine ligament. The uterine artery is held by vessel tape as a mark. The ureter is retracted laterally at the point of the caudal site of the uterine artery. (Reproduced with permission from Fujii T, Aoki D. In: Konishi I, Hiramatsu Y, Sakuragi N, Takeda S, eds. OGS NOW, No.5. (Japanese). Tokyo: Medical View; 2011:86-93. Copyright ( Medical View.)

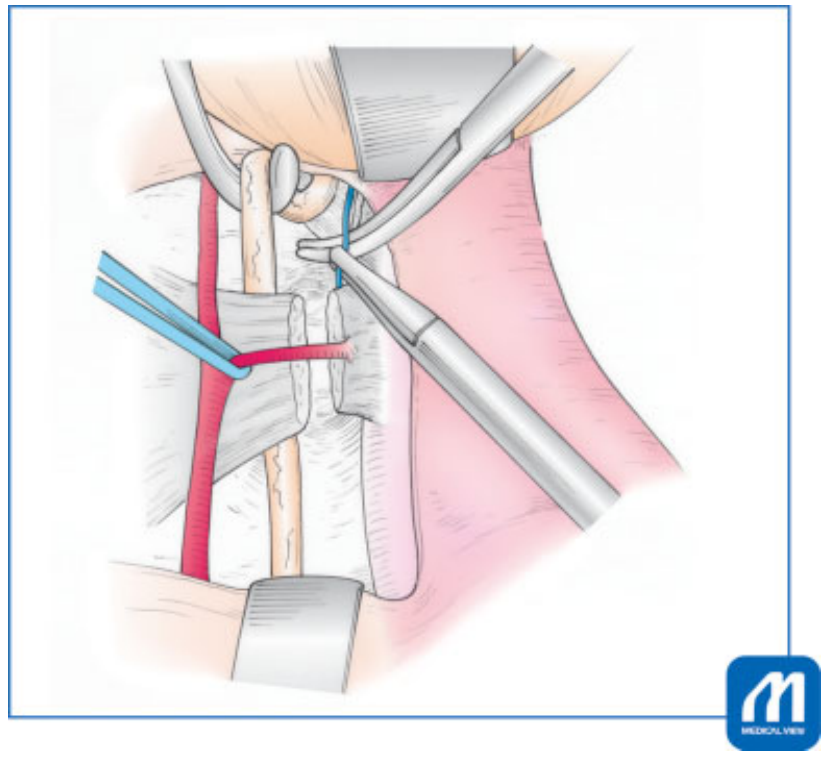

Fig. 4 Cutting and dividing the posterior leaf of the vesicouterine ligament. The ureter is retracted caudally to spread the space for cutting the vessels inside the posterior leaf of the vesicouterine ligament. (Reproduced with permission from Fujii T, Aoki D. In: Konishi I, Hiramatsu Y, Sakuragi N, Takeda S, eds. OGS NOW, No.5. (Japanese). Tokyo: Medical View; 2011:86-93. Copyright $\odot$ Medical View.)

of the tumor. The paracolpium and the wall of the lower vagina are clamped by Leibinger forceps to hold the stump of the vagina. The vaginal wall, between forceps placed cranially (Wertheim) and caudally (Leibinger), is then opened ( - Fig. 5). The paracolpium and the stump of the vaginal edge are sutured for hemostasis and sizing of the vaginal wall to fit the neocervix.

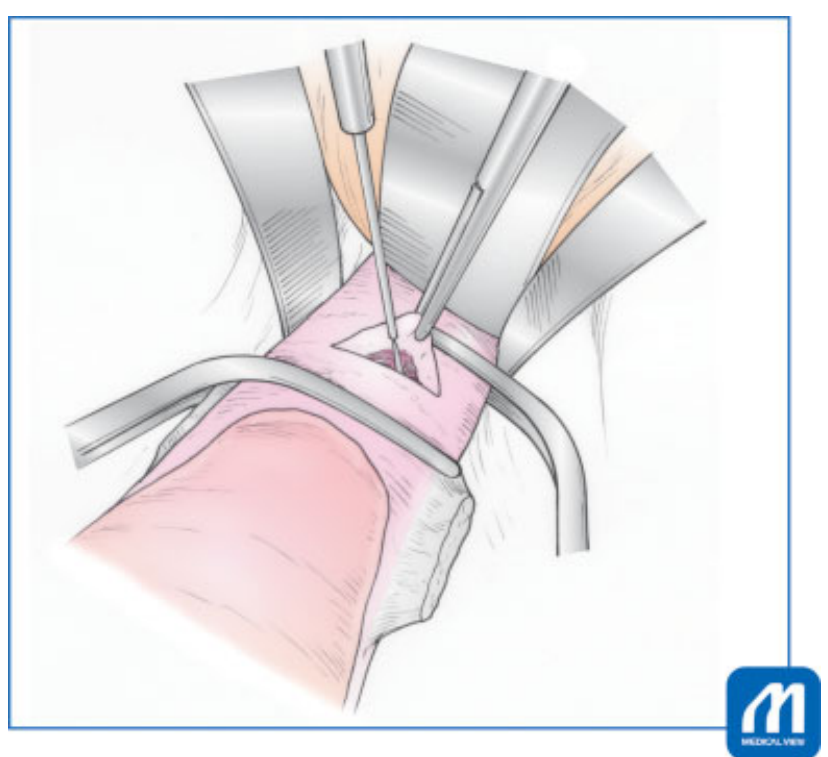

Fig. 5 Opening the vaginal wall between the forceps. Clamped Wertheim forceps over the vagina prevent spillage of the tumor. (Reproduced with permission from Fujii T, Aoki D. In: Konishi I, Hiramatsu Y, Sakuragi N, Takeda S, eds. OGS NOW, No.5. (Japanese). Tokyo: Medical View; 2011:86-93. Copyright @ Medical View.) 


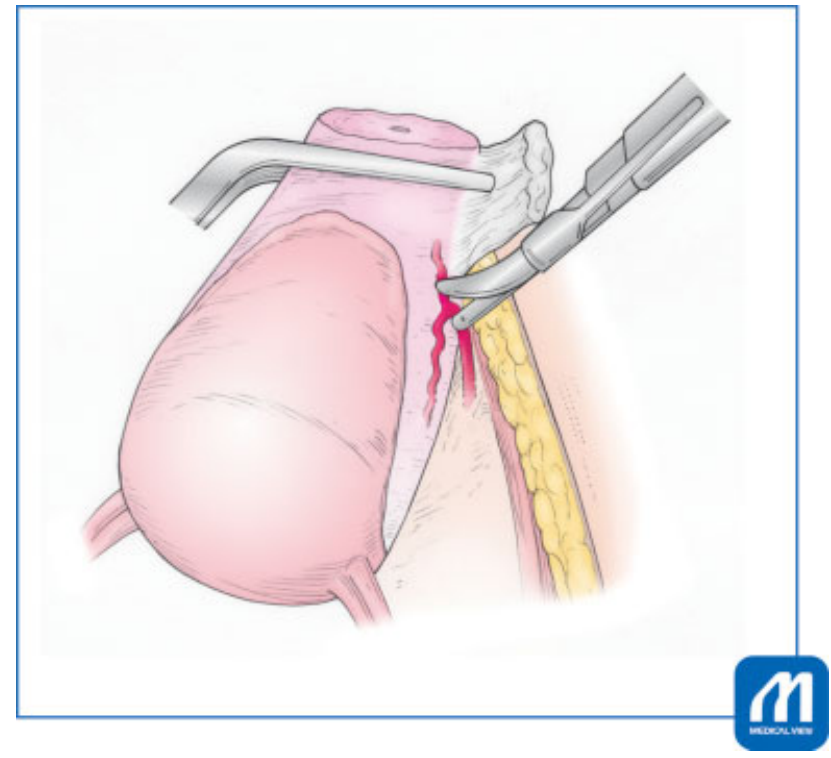

Fig. 6 The caudal branch of the uterine artery is cut with a BiClamp instrument and scissors. The uterine body is retracted in the ventral and cranial direction, and at the same time surgeons take care that the uterine artery not be torn. (Reproduced with permission from Fujii T, Aoki D. In: Konishi I, Hiramatsu Y, Sakuragi N, Takeda S, eds. OGS NOW, No.5. (Japanese). Tokyo: Medical View; 2011:86-93. Copyright @ Medical View.)

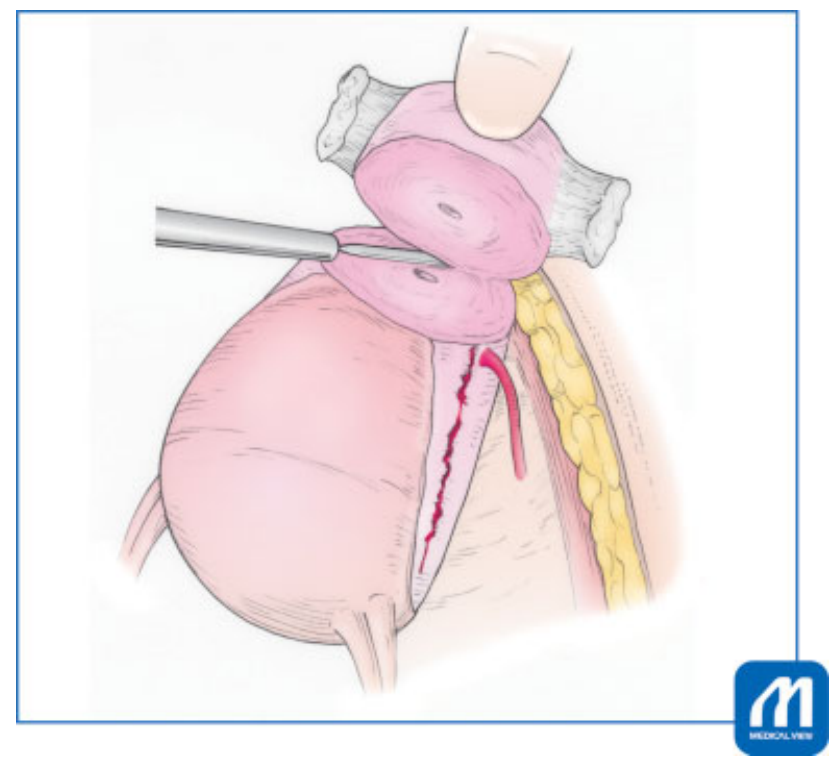

Fig. 7 Dissection of the cervix with an electric scalpel. The cervical stroma is sharply dissected using an electric scalpel in "cut" mode. (Reproduced with permission from Fujii T, Aoki D. In: Konishi I, Hiramatsu Y, Sakuragi N, Takeda S, eds. OGS NOW, No.5. (Japanese). Tokyo: Medical View; 2011:86-93. Copyright $\odot$ Medical View.)

5. Partial resection of cervix: the caudal branch of the uterine artery is sacrificed using a BiClamp instrument (Erbe Elektromedizin GmbH, Tübingen, Germany) (-Fig. 6) followed by cervical tissue dissection with scissors, laterally to medially. When the cervical stroma is clearly exposed, the partial cervix is dissected using an electric scalpel ( - Fig. 7). Additional cervical tissue is dissected by cold scalpel for frozen sectioning ( - Fig. 8).

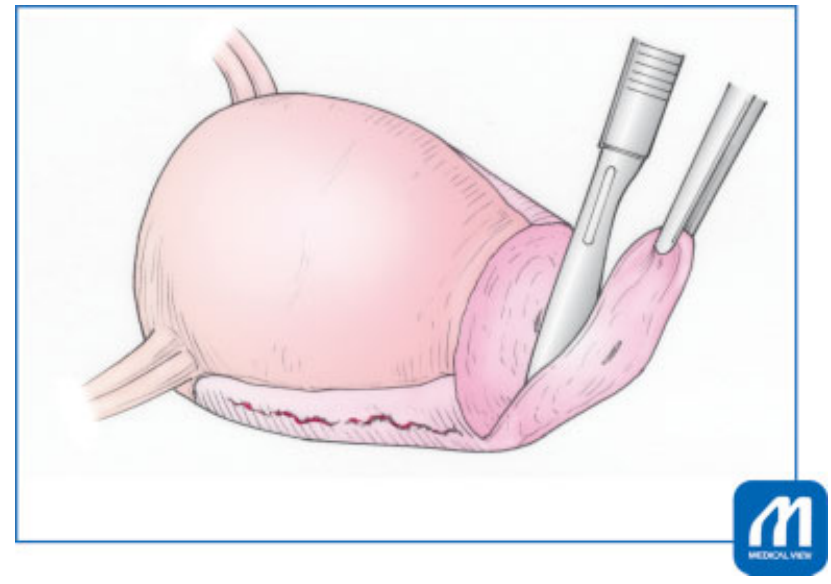

Fig. 8 Dissection of the cervix for frozen sectioning with a cold scalpel. The critical point is that the surgical margin is negative. (Reproduced with permission from Fujii T, Aoki D. In: Konishi I, Hiramatsu Y, Sakuragi N, Takeda S, eds. OGS NOW, No.5. (Japanese). Tokyo: Medical View; 2011:86-93. Copyright ( Medical View.)
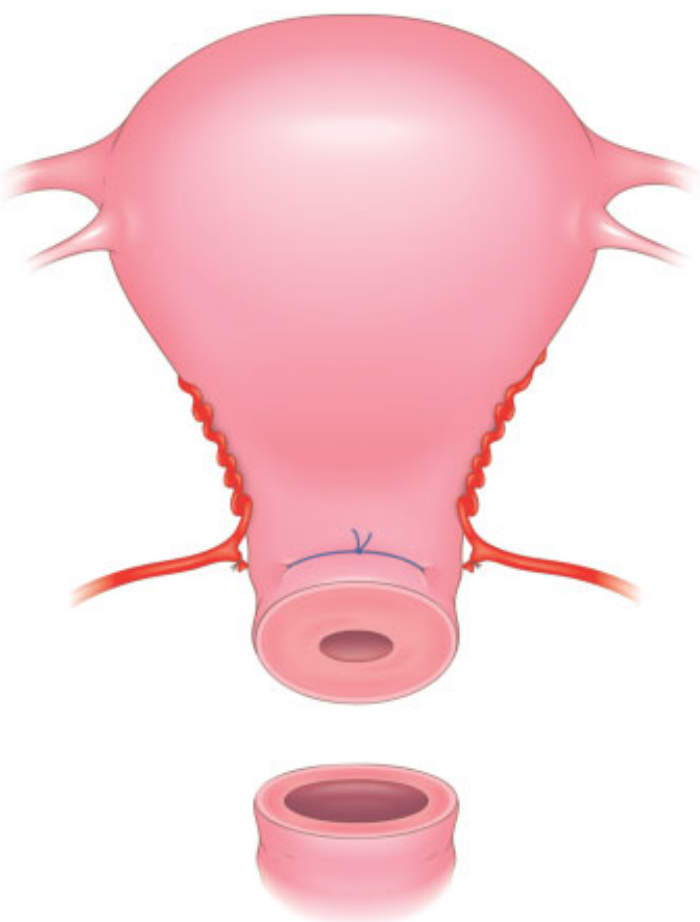

Fig. 9 Neocervix plasty, step 1: neocervical cerclage. The cervical serosa is peeled from the stroma, and the cerclage strings are placed inside the serosa.

6. Neocervix plasty including cerclage and anastomosis of the neocervix to the vagina: after confirmation that the surgical margin is free of tumor, the uterine cavity is determined using a sounding probe at least $45 \mathrm{~mm}$ in length. The serosa of the uterine body is separated from the stroma over the entire circumference. Cerclage to prevent premature delivery is placed in the caudal aspect of the stroma of the neocervix with 1-0 Ethibond suture (Ethicon Inc., Somerville, New Jersey, United States) (-Fig. 9). The cervical ostium flap is created by crosscutting and everting (-Fig. 10). It is important to keep a distance between cerclage strings (1-0 Ethibond) and 


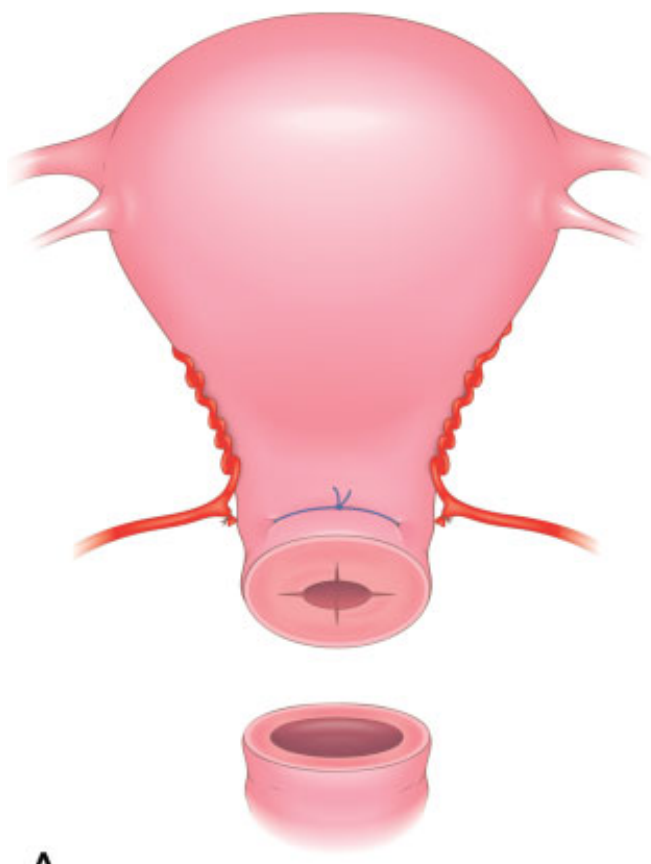

A

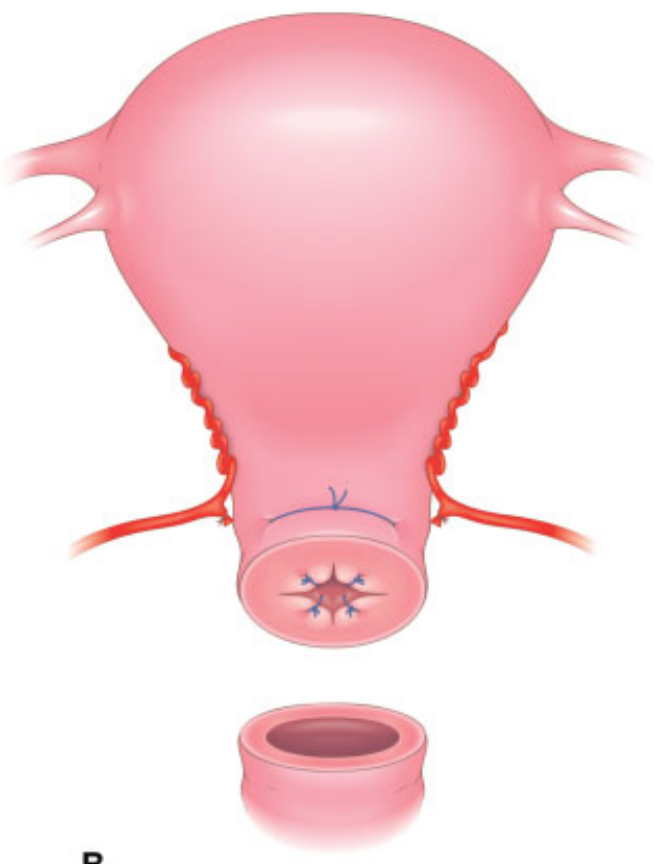

B

Fig. 10 Neo-cervix plasty, step 2: everting and fixing the cervical ostium flap as created by the crosscut incision. (A) After crosscut incision. (B) New cervical O-S is created by a crosscut incision followed with fixing by 4-0 monofilament absorbable strings.

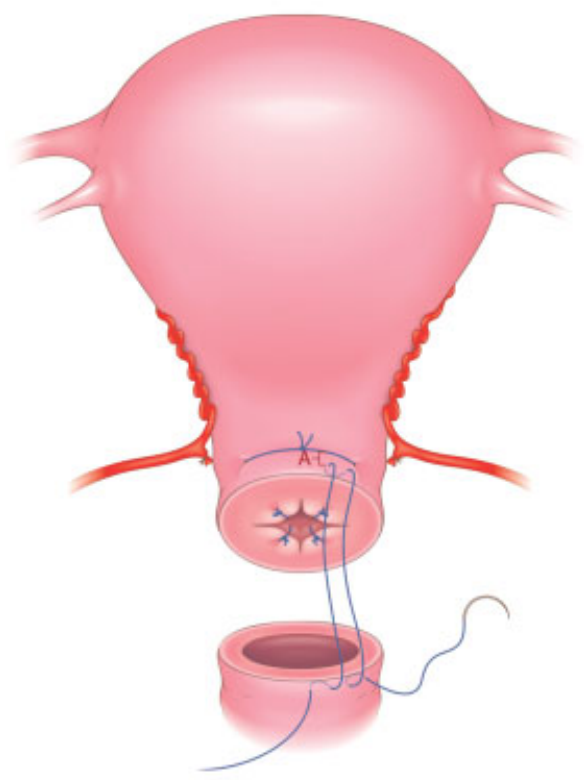

A

Fig. 11 Neocervix plasty, step 3: the distance between the cerclage and anastomosis strings is critical. (A) The influx route of the uterine artery to the cervix is intact. The distance between the cerclage and anastomosis strings is narrow. (B) The influx route of the uterine artery to the cervix is mobilized in the cranial direction. The cerclage strings are placed on the same level as the influx route of the uterine artery and above. The distance between the cerclage and anastomosis strings is wide. We preferred (B) procedure. 


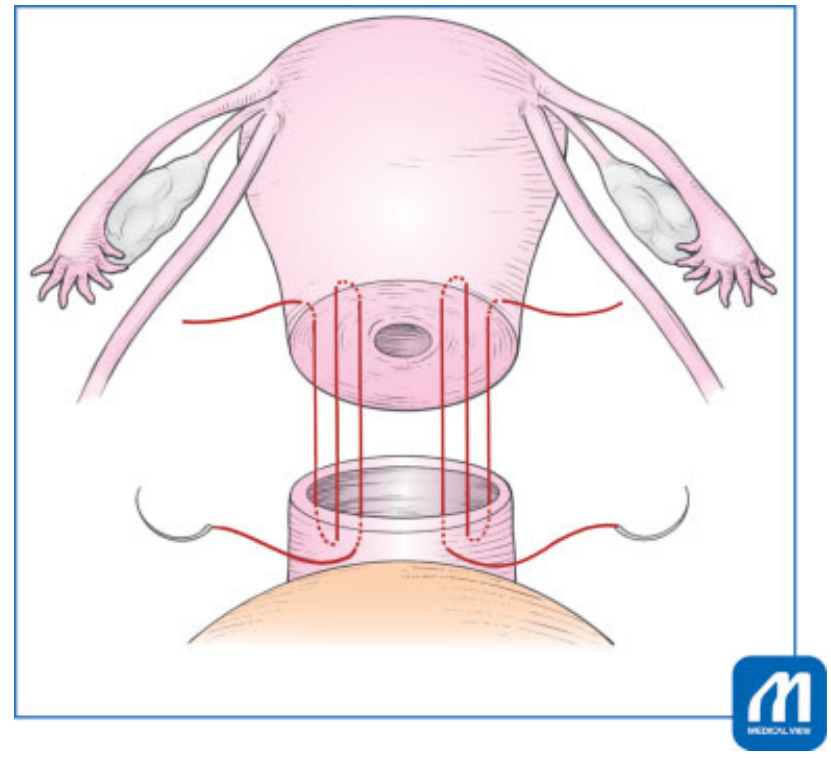

Fig. 12 Diagram of the anastomosis of the neocervix and vagina. A total of four sutures using 1-0 PDS are placed, two each in the anterior and posterior walls of the vagina. The neocervix protrudes from the vaginal cuff. (Reproduced with permission from Fujii T, Aoki D. In: Konishi I, Hiramatsu Y, Sakuragi N, Takeda S, eds. OGS NOW, No.5. (Japanese). Tokyo: Medical View; 2011:86-93. Copyright (c) Medical View.)

anastomosis strings (1-0 PDS [polydioxanone] suture, Ethicon Inc.) (- Fig. 11), otherwise cerclage strings could become infected. In - Fig. 11B, the schema indicates the appropriate distance between the two strings. The exposed stroma of the neocervix is anastomosed to the vaginal wall in at least four sites with 1-0 PDS (-Fig. 12). Additional sutures may be necessary to adapt the vaginal wall.

7. Closure of anterior and posterior retroperitoneum and opening of lateral retroperitoneum: the dorsal portion of the retroperitoneum adjacent to the infundibulopelvic ligament is closed. The bladder peritoneum is closed between the right and left stumps of the round ligaments. The exposed stroma of the neocervix with cerclage is covered by uterine serosa, which is anastomosed to the bladder peritoneum and serosa of the rectum. The lateral portion of the retroperitoneum is kept open to prevent lymphocyst formation. After washing the pelvic cavity with saline, an adhesion barrier such as Seprafilm (Genzyme Corp., Cambridge, Massachusetts, United States), is placed on the repaired retroperitoneum or adnexae.

8. Closure of the abdomen: the edge of the drain is placed on the bottom of the retroperitoneal space. The ileocecum covers the open space of the right side of the retroperitoneum to prevent adhesion of the ileum to the retroperitoneal space. The sigmoid colon covers the open space on the left side of the retroperitoneum. The intestines are arranged in the correct anatomical position to prevent ileus.

\section{Tips}

Resection of the length of cervix is critical. A remnant of a large proportion of the neocervix is at risk for residual disease, but the advantage is the fertility-sparing result. In contrast, a small neocervix has the advantage of decreasing residual disease but is a risk for fertility treatment and perinatal outcome.

Conflict of Interest

None declared.

Acknowledgment

We thank Andrea Baird, MD, from Edanz Group (https:// en-author-services.edanzgroup.com/) for editing a draft of this manuscript.

\section{References}

1 Ramirez PT, Schmeler KM, Soliman PT, Frumovitz M. Fertility preservation in patients with early cervical cancer: radical trachelectomy. Gynecol Oncol 2008;110(03, Suppl 2):S25-S28

2 Dargent D, Martin X, Sacchetoni A, Mathevet P. Laparoscopic vaginal radical trachelectomy: a treatment to preserve the fertility of cervical carcinoma patients. Cancer 2000;88(08):1877-1882

3 Smith JR, Boyle DC, Corless DJ, et al. Abdominal radical trachelectomy: a new surgical technique for the conservative management of cervical carcinoma. Br J Obstet Gynaecol 1997;104(10): 1196-1200

4 Nishio H, Fujii T, Kameyama K, et al. Abdominal radical trachelectomy as a fertility-sparing procedure in women with earlystage cervical cancer in a series of 61 women. Gynecol Oncol 2009;115(01):51-55 